\title{
"CONSTRUINDO A 'ORDEM ANÁRQUICA': ALGUMAS CONSIDERAÇÕES EM TORNO DA DOUTRINA SOCIAL DE PROUDHON E BAKUNIN
}

Patrícia PIOZZI*

RESUMO: Este artigo pretende examinar alguns aspectos da doutrina social de Proudhon e de Bakunin, procurando relacioná-los com suas propostas de transformação social.

UNITERMOS: Anarquia; ordem; revolução; razão; história; natureza.

\section{INTRODUÇÃO}

Ao tratar do surgimento da sociologia como área específica do conhecimento, em seu livro $A$ Era do Capital, Eric Hobsbawm aponta para a importância que as imagens oriundas da biologia adquiriram no pensamento social do século XIX. Cita, especificamente, a analogia entre sociedade e corpo, na qual indivíduos e grupos figuram entrelaçados por um vínculo orgânico de natureza funcional (Cf. 4, cap. 14).

No final do século XVIII, quando a crise do velho mundo chega ao ápice, a imagem do corpo social inspirou não apenas os conservadores que reagiam às mudanças trazidas pelo Iluminismo e pela Revolução Francesa, mas, também, homens do campo progressista, como Rousseau e, mais tarde, Robespierre e Saint-Just. Esses "revolucionários românticos", na expressão de Hobsbawm, uniam, em seu pensamento e atuação políticos, a aspiração à unidade e harmonia sociais com a fé no triunfo das concepções libertárias do Iluminismo. Reagiam, dessa forma, à razão calculista de seu tempo, acusada de colocar os ditames do interesse individual acima do bem comum. Incorporando fundamentalmente

* Departamento de Ciências Sociais Aplicadas à Educàção (Decisae)-Faculdade de Educação (FE) - UNICAMP-13081 - Campinas-SP. 
as teses liberais da igualdade e liberdade naturais, opunham-se, porém, à concepção da sociedade como o lugar onde os indivíduos mônadas, livres de vínculos de obrigação mútua, movidos apenas pelo interesse, exercem sua capacidade de atingir fins. Queriam ver nascer um mundo isento de conflitos, onde liberdade e cooperação convivessem harmonicamente. Tal aspiração está presente na proposta rousseauniana de um "corpo político" de livres e iguais.

Não caberia, evidentemente, incluir a teoria de Rousseau entre as interpretações naturalistas e organicistas do social, já que concebe a sociedade como fruto de uma opção racional e, como a arte de conciliar os interesses individuais com os fins coletivos, o fazer político. No entanto, seus escritos estão permeados pela vontade de instaurar (ou restaurar) um mundo em que o indivíduo se sinta e atue primordialmente como parte de uma totalidade. "O homem civil não é senão uma unidade fracionária que se atém ao denominador, e cujo valor está em sua relação com o inteiro, que é o corpo social" (9, p. 249). Se, por um lado, o ingresso no estado civil configura o abandono da condição natural, na qual o indivíduo encontra-se soberano em sua solidão, por outro lado, a "virtude" do cidadão tem seu correlato natural na piedade, o sentimento inato que vincula cada homem à espécie. Portanto, a ordem civil, ainda que seja obra de uma decisão livre e racional, constitui, também, o desenvolvimento de uma tendência orgânica da espécie à unidade. A má sociedade, aquela que se organiza em torno dos interesses de suas partes, perverte a ordem natural das coisas. A linha divisória entre os homens bons e os malvados se define a partir da relação que esses mantêm com a totalidade. "Onde há inteligência e sentimento, há sempre alguma ordem moral. A diferença é que o bom se ordena tendo o todo como referencial, enquanto o malvado organiza o todo visando a si próprio". $(9, \mathrm{p} .602)$

A negação do individualismo desenfreado em nome do equilíbrio social, tão central na obra de Rousseau e na atuação política dos jacobinos, aprofunda-se e adquire novas dimensões nas elaborações intelectuais dos críticos do liberalismo do século XIX (Nota 1). Nas primeiras décadas começam a ser questionadas as teses da economia política clássica, sintetizadas na conhecida imagem da "mão invisível", de Adam Smith, que figurava a harmonização entre o jogo livre e espontâneo dos interesses individuais no mercado e uma ordem estável, baseada no bem-estar geral. O otimismo em torno das supostas potencialidades do capitalismo industrial em gerar o progresso e a felicidade humana é abalado pelo crescimento assustador da miséria. $\mathrm{O}$ agravamento das condições de vida das populações urbanas entre 1815 e 1840 refreava o otimismo e "... estimulara a investigação crítica, especialmente sobre a distribuição em contraste com a produção, que havia sido a preocupação maior da geração de Adam Smith" (3, p. 260). No campo político aprofundam-se as divergências entre os inimigos do rei. A grande burguesia apóia os "governos da elite de proprietários", as correntes de matriz jacobina propõem as "democracias de base popular". Ao mesmo tempo que o cartismo na Inglaterra, as revoluções de 30 e 48 no continente trazem à tona o operariado industrial como força política independente. Neste contexto de crise e incerteza, formou-se a geração de intelectuais progressistas que inclui os "socialistas utópicos" e os herdeiros do "comunismo 
primitivo". Em que pesem suas diferenças fundamentais de concepção, confluíam para produzir a imagem de uma sociedade futura em que coexistissem progresso e cooperação. Dentre eles, os pioneiros da doutrina social anárquica ousaram pensar uma ordem social de "livres e iguais", isenta de qualquer tutela ou autoridade, viesse ela de Deus, da sabedoria ou até mesmo do consenso popular. Uma ordem baseada na adesão dos homens aos ditames da Natureza a da Razão.

\section{BAKUNIN, PROUDHON E "ORDEM ANÁRQUICA"}

A figuração da sociedade como um corpo é essencial para o desenvolvimento das teses de Proudhon em $O$ que é propriedade, o opúsculo que o tornou famoso em 1841. Fundindo ecleticamente as concepções igualitárias e racionalistas com outras oriundas do organicismo romântico, o autor imagina a sociedade como um organismo complexo, que funciona pelo concurso de vocações e talentos diversificados, sem que essa diferença implique desigualdade econômica e social. Ao contrário, a divisão do trabalho propicia o desenvolvimento pleno das inclinações e capacidades, ao mesmo tempo em que garante a coesão do todo. Diferença e complementariedade realizam-se na troca livre e igualitária dos produtos. Sobrepondo os critérios qualitativos oriundos da analogia biológica com os quantitativos extraídos das ciências matemáticas, Proudhon argumenta que cada um dos trabalhos é igualmente útil à higidez do todo, e que, do ponto de vista da medição abstrata, a capacidade de produzir no tempo difere muito pouco de homem a homem. Conclui que a desigualdade econômica é impossível, contrária à "lógica dos fatos" e às "leis da economia". Nos escritos posteriores, a idéia, central em seu pensamento, de que a igualdade fundamenta-se em leis objetivas é representada pela equação heterodoxa segundo a qual todos os trabalhos são iguais na proporcionalidade dos talentos.

O segundo argumento do autor refere-se ao fundamento psicológico da cooperação social. O homem, ser social por necessidade, o é também por instinto, sendo "...movido por uma inclinação interior para o seu semelhante, uma secreta simpatia que o faz amar e condoer-se de maneira que para resistir a essa inclinação é preciso um esforço da vontade contra a natureza" (7, p. 198). Na esteira de Rousseau, Proudhon aponta que o sentimento social, inato e indestrutível, desenvolve-se com o auxílio da experiência e do raciocínio até que os corações e mentes compreendam e incorporem a lei fundamental que governa a vida humana: a Justiça, isto é, a igualdade dos trabalhos na proporcionalidade dos talentos. "Como faculdade, ela (a justiça) é suscetível de desenvolvimento que constitui a educação da humanidade. Como equação, ela não apresenta nada de antinômico; ela é absoluta e imutável como toda lei e, ainda, como lei, altamente inteligível" (2. p. 252).

Em si imútavel e eterna, a Justiça é também uma conquista da aventura humana no tempo. O caminho do homem rumo à realização de sua essência social é, porém, profundamente marcado pela presença do irracional e da iniqüidade. Violência, engano, domínio, exploração, crimes são permanentes ao longo da história humana. Proudhon atribui a origem dessas "patologias" à natureza complexa do organismo social, à dualidade 
da psique humana e às dificuldades de aprendizagem da razão. Em sua explicação, de ordem lógica, a diferença dos talentos, unida à ignorância de seu destino social e ao prevalecer das paixões egoístas sobre a sociabilidade, propicia a hipertrofia do "eu individual", rompendo o equilíbrio orgânico da vida. A emergência da propriedade e da exploração do trabalho concretizam a ruptura. A partir deste "pecado original", começa a degradação e morte do corpo social. Campo da "guerra de todos contra todos", a sociedade de classes tem como princípio organizador a vontade subjetiva, arbitrária, governada pelo interesse de indivíduos e grupos. É a "aristocracia dos mais fortes", que tem por correlato o ressentimento dos mais fracos. Nesse contexto, a política aparece como "...a arte equívoca e incerta de estabelecer a ordem numa sociedade onde todas as leis da economia são desconhecidas, todo o equilíbrio destruíde, toda a liberdade reprimida" (5, p. 264). Isto é: um instrumento artificial, mecấnico, que mantém coesa, pela força e pelo engano, uma sociedade dilacerada pelos antagonismos.

$\mathrm{O}$ vigor das imagens que retratam a decadência moral trazida pelo advento do capitalismo, a condenação das lutas de classe, revelam, mais que identificação com os sofrimentos e reivindicações da classe operária nascente, o espanto do camponês ou do artesão diante do desagregar-se dos vínculos orgânicos com a natureza, com o instrumento de trabalho, com os costumes seculares. As investidas contra os defensores do comunismo dos bens, feitas em nome da liberdade e propriedade pessoais, expressam o apego do pequeno empreendedor às posses ganhas com o "suor da testa", mais que o humanista preocupado com a liberdade de pensamento.

Os limites do libertarismo de Proudhon desvendam-se cristalinamente nos textos que traçam o perfil da nova ordem (Cf. 5, 7, 8). Neles, a "anarquia" é figurada como superação e síntese dos regimes de comunidade e propriedade, como o sistema em que liberdade individual e cooperação coexistem sem conflito. Inimigo de "...toda doutrina que aspira secretamente à prepotência e à imutabilidade... que se lisonjeia por dar a última formulação da liberdade e da razão..." (6, p. 117). Proudhon é freqüentemente citado entre os pensadores socialistas que mais se preocupam com a preservação e o desenvolvimento da autonomia individual no interior do novo sistema. As concepções autogestionárias na economia, a idéia de revolução como mudança inf inita, as propostas de cunho federalista na política, contribuem para inscrevê-lo entre os fundadores do chamado socialismo libertário. Porém, olhando um pouco mais de perto a ordem social por ele propugnada, aparece o quadro de um "organismo saudável", que produz sua existência pelo trabalho cooperativo de seus órgãos. Estes cumprem voluntariamente sua função e dividem o produto igualitariamente, segundo uma norma de justiça universal, supra-histórica, modelo de convivência que os homens platonicamente reencontram em si. Apesar da crítica a todas as formas de dogmatismo e imobilismo, Proudhon concebe a história em chave escatológica: o movimento de renovação permanece definido por um destino previamente traçado e na ordem que enfim realiza plenamente este destino, a liberdade continua prisioneira da norma geral, entendida não como produção das opções dos homens, mas como ditame de uma razão cósmica. Seu universo isento de conflitos não é povoado por indivíduos autônomos que interagem, refletem, divergem, procuram um acordo. A 
harmonia desse universo nasce do reconhecimento, por parte de cada indivíduo, de sua essência última de "animal social", o que significa reconhecer a identidade de interesses de todos na infinita variedade das funções (Nota 2).

Enfim, no plano das propostas específicas, a emergência do novo sistema aparece vinculada a um conjunto de mudanças nas relações sociais vigentes no capitalismo.

No que diz respeito às relações de distribuição, o mutualismo, isto é, a implantação da lei orgânica de ajuda mútua na economia de troca, implica a abolição da propriedade capitalista, porém conserva a propriedade fundada no trabalho, o mercado livre e a concorrência, desde que subordinados à lei do justo preço. A interpretação proudhoniana do mecanismo de constituição do capitalismo está centrada nas idéias de força bruta, usurpação, roubo, mentira. Presa a essa genealogia moral das relações capitalistas, não problematiza o fato de que a igualdade jurídica, a liberdade de dispor do próprio corpo, a propriedade legitimada pelo trabalho são idéias constitutivas do sistema. Considerando-as abstratamente, separadas de sua gênese histórica, Proudhon não ataca os fundamentos lógicos do pensamento burguês, e sua crítica desemboca numa proposta de reforma dos "excessos do sistema".

Quanto à problemática da produção social, a divisão do trabalho é tratada como uma necessidade natural, por analogia com o organismobiológico. O problema da mecanização e fragmentação do trabalho humano na fábrica se resolve, por um lado, pela reforma da propriedade e da distribuição das rendas; por outro, pela educação dos trabalhadores. Esta deverá ser enciclopédica e não apenas especializada. O operário assim educado poderá localizar seu lugar na cadeia que liga todos os trabalhos entre si, dentro e fora da fábrica, e dessa forma deixar de ser apenas peça de um mecanismo cujo fim e controle lhe são estranhos para tornar-se membro de uma totalidade orgânica. Tendo seus interesses articulados com os do todo, entendendo o sentido e fim de sua tarefa, sente-se obrigado a cumpri-la, não por uma necessidade imposta externamente, mas como membro ativo e responsável do corpo social.

No plano político, a substituição dos aparatos repressivos e das leis positivas pelos livres contratos das comunas e federações vincula-se à obediência voluntária às normas da solidariedade e da justiça, necessidade ditada pela natureza ao coração e incorporada pela razão ao longo da história. Nestes termos, reduzida a política à administração das coisas públicas, não há lugar para discussões ou organizações político-ideológicas. Nas palavras de Proudhon: "Baseado na prática espontânea do trabalho, o novo sistema é o sistema de direitos humanos. Opondo-se à autoridade arbitrária e essencialmente objetivo, ele não permite a criação de partidos nem seitas; é um organismo que se basta a si mesmo e não admite restrições nem divisões". (8, p. 205)

Caberia perguntar de que forma a "ordem anárquica" irá manter o equilíbrio entre cooperação e liberdade se funções objetivas e desejos se dissociarem. Este dilema está presente no pensamento de Proudhon, que, ao lado da confiança na força da racionalidade humana, mostra pessimismo em relação à capacidade de renovação da sociedade 
degradada. Em inúmeras passagens, insurge-se contra os apetites animalescos de ricos e pobıes, contra a vileza e ignorância da plebe, ora afirmando que o homem é um ser malformado, ora que sua degradação é irreversível.

Mais que explorar a possível incongruência lógica de suas teses, interessa, a nosso ver, procurar entendê-la no interior da problemática que a história do século coloca aos propositores da reforma social. Como outros "revolucionários românticos" de seu tempo, Proudhon carrega a nostalgia dos vínculos orgânicos com a natureza e dos valores comunitários do mundo pré-industrial, ao mesmo tempo em que está impregnado do espírito racionalista e cientificista também característico da época. Fundem-se nele o moralismo pessimista de Rousseau e o otimismo cientificista de Comte. Produz-se um hibridismo entre o filósofo da história, confiante no inexorável destino do homem para a verdade, e o crítico desolado dos males de seu tempo. Em sua última obra, $A$ capacidade política da classe operária, Proudhon "resolve" a tensão entre a lógica da necessidade histórica traçada pela teoria e as incertezas e engodos das conjunturas empíricas, identificando nos movimentos de ajuda mútua e resistência do operariado o sinal da regeneração da sociedade. Segundo sua genealogia da Revolução, as revoltas periódicas dos pobres contra a propriedade fazem parte de um movimento orgânico, espontâneo, da vida universal em luta contra os elementos de desagregação e morte da sociedade. A Revolução Francesa marcaria, nesta ótica, o nascimento da consciência plebéia que, com o advento do industrialismo, estaria amadurecendo nas formas de democracia operária. $\mathrm{O}$ associacionismo, princípio regulador dos movimentos de ajuda mútua, aparece como prenúncio e modelo da nova ordem. Investidos da missão de restabelecer a solidariedade no organismo social, as instituições e os movimentos de trabalhadores devem ter caráter ecumênico e fundamentalmente pacífico.

Escrita poucos meses antes de sua morte, ocorrida em 1865, A capacidade política da classe operária tornou-se o testamento político de Proudhon. Nele, reconhecia no operariado o portador do Universal e lhe legava a tarefa de mostrar à humanidade as normas da Justiça. Assim, ao saudar as primeiras candidaturas operárias independentes ao parlamento francês, o autor imagina um futuro muito próximo, no qual a proposta mutualista estaria definitivamente incorporada pela sociedade (Nota 3). Quinze anos mais tarde, a primeira tentativa proletária de criar uma nova organização do trabalho era reprimida com extrema violência na França republicana.

As duas décadas que separam a morte de Proudhon da de Bakunin são marcadas pelo nascimento e fim da primeira Internacional e pelo advento da Comuna de Paris, seguidos por um período de reação e passividade das massas. Ao longo destas décadas, Bakunin formula as idéias que justificam sua inclusão entre os clássicos da doutrina anarquista.

Tendo voltado à Europa Ocidental em 1858, após uma longa e aventurosa fuga da Sibéria, nos anos imediatamente posteriores, o revolucionário russo abandona as teses pan-eslavistas, adere ao internacionalismo proletário e aprofunda suas críticas a todas as formas de poder e de exploração, propugnando a abolição do Estado e da propriedade privada. Os escritos desta fase revelam uma alternância irresolvida entre a fé no progresso 
inexorável da razão e o pessimismo em torno das possibilidades de renovação da sociedade degradada. Esta ambigüidade cristaliza-se, de certo modo, em sua concepção de revolução: movimento orgânico de regeneração da sociedade, carrega a necessidade da violência e da destruição do existente. Como Proudhon, Bakunin projeta no futuro a imagem do organismo social harmônico, ponto final do "caminho do humem da bestialidade à humanidade". No entanto, revela grande influência das concepções marxianas ao considerar o conflito de classe fundamental na dinâmica da revolução. Porém, apesar desse acento na ordem das necessidades, que o aproxima do "materialismo" de Marx, de modo geral prevalece, em sua interpretação do processo revolucionário, o ponto de vista ético e idealista. Assim, concebe a violência destrutiva não como uma decorrência da oposição das forças em jogo, de caráter mecânico ou instrumental, mas como uma missão purificadora - e aterradora-, imprescindível para a regeneração da humanidade. A revolução, movimento espontâneo e fatal da liberdade humana em direção à conquista de sua plenitude, manifesta-se, construtivamente, nas formas de solidariedade e cooperação dos povos e dos trabalhadores; negativamente, nas rebeliões e insurreições de massa. Estas configurações empíricas da liberdade ao longo da história mostram seus dois lados opostos e complementares: 1) o respeito mútuo, pelo qual o indivíduo reconhece no outro um ser igual no plano do trabalho e dos direitos e deveres, 2) a destruição dos que violam as leis da natureza, usurpando a liberdade de seus iguais. Desta forma, a insurreição violenta das massas contra a propriedade e o Estado não apenas legitima-se num direito natural; configura-se também como uma missão ditada pelas leis da vida.

Os escritos em defesa da Internacional em resposta aos ataques de Mazzini, datados entre 1869 e 1872 (1) revelam mais claramente a oscilação de Bakunin entre a fé no triunfo inelutável da revolução e a descrença na capacidade da sociedade de se regenerar. Ao mesmo tempo em que saúda a Internacional como o mais alto resultado na organização da solidariedade operária, aponta os limites da ação espontânea. As massas proletárias, figuradas como força pura da natureza, imune à contaminação da riqueza e do poder, mostram-se, no entanto, aos seus olhos de homem culto, ignorantes e embrutecidas pelo trabalho. Solidárias e rebeldes por "instinto e condição", não detêm a ciência do real. Vítimas da "força e mentira" dos poderosos, acostumaram-se a obedecer e são incapazes de uma crítica global à sociedade.

Sem negar radicalmente suas convicções espontaneístas, o crítico implacável das nascentes burocracias operárias reafirma que a experiência histórica direta educa as massas e as conduz ao caminho da revolução. Realçando, porém, que a aprendizagem por experiência própria é "desoladoramente lenta", defende a necessidade de criar uma organização de revolucionários-cientistas, um instrumento artificial, com a finalidade de acelerar o processo espontâneo por um trabalho sistemático de propaganda, educação e exemplo. Os membros dessa organização deveriam romper todos os vínculos econômicos e pessoais com a sociedade burguesa e devotar-se integralmente à causa. A renúncia às relações, aos desejos e interesses privados, e a incorporação da revolução como único fim da vida constituem o militante e configuram a principal garantia contra os perigos de germinação de um novo poder, inerentes a toda organização criada artificialmente. 
Os militantes da "aliança" bakuninista nos evocam os personagens da república platônica, os ascéticos magistrados que exercem o poder sob a condição de nunca usufruí-lo. Sem família nem propriedade, educados para amar exclusivamente a Cidade, não distinguem seus interesses dos do todo. Mais radicalmente até, os revolucionários da "aliança" perdem o direito à visibilidade. Jamais deverão vir à luz do sol, constituindo uma força política independente, já que sua única função é suscitar - ou melhor, apressar a ação e organização autônoma do povo, da qual deverá nascer a nova ordem. Mesmo após a revolução, os núcleos deverão permanecer invisíveis, serão algo assim como vigilantes subterrâneos da liberdade.

A teoria da organização de Bakunin revela, a nosso ver, um esforço para conciliar a crença na espontaneidade do movimento histórico com a necessidade de uma intervenção mecânica. Pode-se levantar a hipótese de que seu pensamento anuncia a crise da crença na instauração de um mundo de livres e iguais, por obra da Razão, encarnada no movimento de transformação social iniciado em 1789. A crise das crenças e concepções evolucionistas e cientificistas, que caracterizaram tão profundamente o pensamento progressista do século XIX, estará no centro do debate dos revolucionários no século XX.

\section{NOTAS}

1- Para uma análise das metáforas do mecanismo e do organismo no pensamento conservador e progressista do século XIX, conferir ROMANO, R. Conservadorismo romântico; origem do totalitarismo. São Paulo, Brasiliense, 1981; e Corpo e cristal; Marx romântico. Rio de Janeiro, Guanabara II, 1985. Os trabalhos do Prof. Romano constituíram referência fundamental em nossa pesquisa e para a redação deste artigo.

2-Para uma análise dos limites do libertarismo na doutrina anárquica, conferir ARAUJO, P.M. Domínio da regra: condição do saber e do agir; considerações sobre as experiências liberal e anarquista na República. Belo Horizonte, Faculdade de Educação da UFMG, 1988 (Dissertação de mestrado). A análise de Araujo, que conhecemos ao longo da redação deste trabalho e que versa sobre autores posteriores a Proudhon, aponta alguns problemas na teoria libertária, similares aos que detectamos em nossa leitura de Proudhon.

3-Após a publicação do Manifesto dos 60, pelo qual importantes líderes mutualistas manifestavam seu apoio às candidaturas operárias de Paris, Proudhon, apesar de manter a posição abstencionista, reconheceu nelas o primeiro momento de separação e independência política do operariado em relação aos partidos burgueses. 
PIOZZI, P. - "Les architectes de 'l'ordre anarchique": quelques consicierations à l'égard de la doctrine social de Proudhon et Bakunin. Trans/Form/Ação, São Paulo, 13: $11-20,1990$.

RÉSUMÉ: Cet article a l'intention d'examiner quelques aspects de la doctrine sociale de Proufhon et Bakounine en faisant le rapport avec leurs propositions de transformation sociale. UNITERMES: Anarchie; ordre; révolution; histoire, nature.

\section{REFERÊNCIAS BIBLIOGRÁFICAS}

1. BAKUNIN, M. Federalismo, socialismo y teologismo. In: Oeuvres complètes. Paris, Champ Libre, 1973.

2. CUVILLIER, A. Proudhon. Paris, Ed. Sociales Internacionales, 1937.

3. HOBSBAWM, E. A era das revoluções. Rio de Janeiro, Paz e Terra, 1977.

4. HOBSBAWM, E. A era do capital. Rio de Janeiro, Paz e Terra, 1977.

5. PROUDHON, P.J. De la justice dans la revolution e dans L'Eglise. (IV étude) In: Oeuvres complètes. Paris, Librairie des sciences Politiques et Sociales, 1931.

6. PROUDHON, P.J. A nova sociedade. Lisboa, Rés, s.d.

7. PROUDHON, P.J. O que é a propriedade? Lisboa, Estampa, 1975.

8. PROUDHON, P.J. Idée Générale de la Revolution are XIX $X^{\circ}$ Siècle, Paris, Federation Anarchistem, 1979.

9. ROUSSEAU, J.-J. Émile ou de l'éducation. In: Oeuvres complètes. Paris, Gallimard, 1964. v.4. 


\section{BIBLIOGRAFIA CONSULTADA}

ANSART, P. El nascimiento del anarquismo. Buenos Aires, Amorrortu, 1970.

ARAUJO, P.E.M. de Domínio da regra; condição do saber e do agir; considerações sobre as experiências liberal e anarquista na República. Belo Horizonte, Universidade Federal de Minas Gerais, 1988. (Tese de Mestrado)

BAKUNIN, M. Bakounine e L'Italie; 1871-1872. In: Oeuvres complètes. Paris, Champ Libre, 1973.

GIRARDET, P. Mitos e mitologias políticas. São Paulo, Companhia de Letras, 1967.

MARX, K. Misère de la Philosophie. Paris, Ed. Sociales, 1972.

PROUDHON, P.J. La capacidad política de la clase obrera. Madrid, Jucar, 1987.

ROMANO,R. Conservadorismo romântico; origem do totalitarismo. São Paulo, Brasiliense, 1981.

ROMANO, R. Corpo e cristal; Marx romântico. Rio de Janeiro, Guanabara II, 1982.

ROSSEAU, J.-J. Le contrat social. In: Oeuvres complètes. Paris, Gallimard, 1964. v.4.

TAWNEY, R.H. A religião e o surgimento do capitalismo. São Paulo, Perspectiva, 1971. 